\title{
Influence of Pulsation Frequency in Iron Oxide Jigging
}

\author{
André Carlos Silva ${ }^{1}$, Raphael Silva Tomaz ${ }^{2}$, Débora Nascimento Sousa ${ }^{3}$, Elenice Maria Schons Silva ${ }^{4}$, \\ Mariana Resende Barros ${ }^{5}$, Thales Prado Fontes ${ }^{6}$ \\ ${ }^{1,4,5}$ Federal University of Goiás, Department of Mine Engineering \\ Av. Dr. Lamartine Pinto de Avelar, 1120, Catalão, Brazil \\ ancarsil@ufg.br; eschons@ufg.br; mrezendeb@outlook.com \\ ${ }^{2,3,6}$ Goiano Federal Institute, Department of Mining \\ Av. Vinte de Agosto, 410, Catalão, Brazil \\ raphael.tomaz@ifgoiano.edu.br; debora.nascimento@ifgoiano.edu.br; thales.prado@ifgoiano.edu.br
}

\begin{abstract}
The importance of pigments for the civilization is obvious and well documented. Although these materials have been discovered many years ago, research continues nowadays. Industries often require new shades, colours and more homogeneous and stable pigments. The selection of mineral pigments is of major importance to acquire high quality, colour, purity and mostly free of chemical contaminants, such as chemicals from froth flotation process. The region of Catalão, Brazil, has several minerals species in the site, including apatite, barite, magnetite, monazite, niobium, titanite and vermiculite. Nowadays phosphate, niobium and barite are economically exploited. For the production of these minerals, the magnetite is removed through magnetic separation and sent to a tailings dam. The aim of this study is to evaluate the possibility of producing iron oxide to be used as pigments as well as to evaluate the pulsation frequency influence in the jigging process. A Denver jig, in lab scale was used. Test were carried out using six different particle sizes and four pulsation frequencies, keeping the water flow rate fixed at 20 litres per minute. The results indicate that iron oxide production for pigments is viable from phosphate rock tailings, since it was possible to produce magnetite concentrated with grades over $90 \%$ and magnetite recovery around $40 \%$.
\end{abstract}

Keywords: iron oxide, jigging, phosphate

\section{Introduction}

Humankind has used colours for more than 20 thousand years. The first dye to be known to humankind was soot, around 3,000 BC. Pigments are insoluble dyes (small corpuscles) in the medium in which they are dispersed. In the case of soluble dyes, the solutions penetrate the material to dye (especially textile), lending it not only colouring but also reacting with this material [1]. The selection of raw materials is of major importance to acquire high quality mineral pigments, colour luminescence and purity, that is, free of chemical contaminants. The usual particle size for pigment industry is around 50 $\mu \mathrm{m}$. However, pigments can be produce by grinding with particle size up to $100 \mu \mathrm{m}$ [2]. Mineral pigments are gaining commercial acceptance because of the growing ecological awareness, in order to reduce environmental impacts caused by production methods generally associated with synthetic ones. The most common mineral pigments are iron oxide, manganite, chromite, quartz, feldspar, monazite, zircon, titania and micas (such as muscovite and biotite) [1].

Magnetite $\left(\mathrm{Fe}_{3} \mathrm{O}_{4}\right)$ is a magnetic oxide of iron formed by natural ions $\mathrm{Fe}^{+2}$ and $\mathrm{Fe}^{+3}$. It is the most common magnetic mineral and is present in small amounts in almost all crustal rocks. Most of the iron ore production in Brazil, by magnetite or hematite processing, is done by froth flotation or magnetic separation. Froth flotation inhibit the use of iron oxide for purposes other than steel production due to the amount of chemicals, particularly surfactants, involved in this process [3]. According to market, the metal load (sinter, pellet or granular) for steel production should contain approximately $65 \%$ of iron in its composition regardless of the mineral (hematite, magnetite, goethite, etc.). For pigments production, it is needed to obtain magnetite with high purity (above 95\%), free from chemical contaminants and with particle size smaller than 100 $\mu \mathrm{m}$.

Jig separation is one of the oldest methods of gravity concentration. Even today, it is the widespread technology in coal preparation because of its high separation precision, cost-effectiveness and high throughput rate. A jig is a gravity separator that uses pulsation (repeated expansion and contraction of a vertical bed of particles) of water. The result of this movement is the bed stratification, where the materials density splits in ascending order from the top to the bottom [4][5]. 
Jigs uses has been documented since De Re Metallica [6] and there are several works describing the use of jigs in fields such as mineral processing and even recycling.

A Denver jig was used to study the effect of three important process parameters on particle segregation during fluidization stage of the jig cycle (maximum water velocity; feed characteristic, such as size ratio, volume fraction and particle size, and frequency of pulsation). The jig was fed with iron ore $(10.0 \mathrm{~mm}$ size fractions) from Joda iron ore beneficiation plant of Tata Steel Limited [7]. A TACUB jig was applied to separate waste plastics used in copy machine. Grades of 99.8\% PS, 99.3\% ABS, and 98.6\% PET were recovered as the products in the top, middle and bottom layers, respectively [5]. In another study with the same jig [8] the separation for crushed plastic particles was tested. Small plastic particles (two types of burn-resistant PE) and PVC with size of 0.5-3 mm and with specific gravities of the two PEs and PVC were about 1.1, 1.3 and 1.4, respectively, were used. The jig separation experiments were carried out under various water pulsations, at which the amplitude, frequency, and pattern of pulsation were varied. High-grade PE and PVC products over 99.8\% were recovered under pulsations of small frequency and amplitude.

In jigging, amplitude and frequency of pulsation, and feed characteristics are the most important process parameters [7]. Although is well accepted that the movement of water through the jig bed is the key to better stratification of particles [9]. Effects of these parameters on particle segregation during jigging are studied and explained through experimental as well as numerical means by drawing parallel to liquid/solid fluidization process. This is permissible because jigging could also be viewed as a repetitive process of fluidization and defluidization [7].

Jigs simulation had been done for many authors in order to better understanding its operation. An instrumented U-tube jig was used in a systematic analysis of the movement of water in it, producing a conventional pressurized pulsion and gravity induced suction cycle. A strong correlation between amplitude and frequency of the water waveform was found, which lead to an increase in the operating range of the frequency of pulsation [9]. Models based on Newtonian mechanics was used to study the stratification behaviour of particles in batch U-tube jigs. The motion of solid particles was treated using the discrete element method (DEM) [10]. Radioisotope tracers were used to verify that the particles in a jig bed not only follow the vertical motion, but also perform a circulatory motion [11]. Evidence of circulatory motion of particles in jigs has been found by following the trajectories of particles using the positron emission particle tracking technique [12]. The fluid motion as well as the coupled particle motion in response to the applied pulsation of water has been numerically studied by several means. DEM was used to track the position of particles and hence determine the degree of stratification [13].

The region of Catalão, Brazil, has occurrence of several different mineral species including apatite, barite, magnetite, monazite, niobium, titanite and vermiculite. Currently Anglo American Phosphates produces apatite and barite both through froth flotation. The company tailings production is around $2 \mathrm{Mt}$ per year with magnetite content around 35\%. The magnetite co-production could bring two major gains. Firstly, the generation of material that can be used for pigments production and secondly the reduction of the amount of material sent to the tailings dam, avoiding the building of new dams and reducing environmental impacts. Gravity concentration methods may be an option to redeem the tailings of phosphate rock for the production of high-grade magnetite. The jig was chosen because of its cost-effectiveness.

\section{Methodology}

Magnetite samples were donated by the Anglo American Phosphates, collected after the low field magnetic separation, a stage previously the phosphate rock froth flotation, and composed by the magnetic concentrate. Quartz sand was used as gang mineral and blended to the magnetite. The choice of quartz sand for the tests was due to its morphology, the chemical composition and density. The quartz sand has a density closes to the apatite and other silicon based minerals present in Anglo American's ore.

The experimental procedure was divided into three stages. Initially magnetite samples were subjected to particle size analysis using laser particle analyser Mastersizer from Malvern, chemical analysis using an X-ray fluorescence spectrometer and analysed using a SEM Jeol JSM 6610 and the punctual chemical composition was determined using an energy dispersive $\mathrm{x}$-ray detector (EDS) Thermo scientific NSS Spectral Imaging. Then magnetite and quartz sand samples at six different granulometry $(-500+300,-300+212,-212+150,-150+106,-106+75,-75+53 \mu \mathrm{m})$ were blended to obtain samples of $400 \mathrm{~g}$ ( $200 \mathrm{~g}$ of each mineral). Finally, the jigging tests were carried out in a laboratory jig Denver model SJ-1015 from Engendrar. This jig has a fixed screen, and a diaphragm provides the water pulsation. A fixed time of two minutes jigging was adopted, being thirty seconds for the jig feeding and 1.5 minutes from the jig process (without any solid feeding). A bed formed by $1.5 \mathrm{~kg}$ of steel balls with $8 \mathrm{~mm}$ diameter was used. The water flow was fixed at 20 litres per minute and the pulsation frequencies were 102, 188, 274, 359 RPM. Both products (light and heavy) were collected, filtered, dried in an oven, 
weighted and then subjected to magnetic separation using a rare earth magnet, as described in the literature [14]. All tests were performed in triplicate, totalling 72 tests.

\section{Results and discussion}

Figure 1 shows the magnetite's particle size analysis. It is possible to see that around $43 \%$ of magnetite is smaller than $100 \mu \mathrm{m}$ and approximately $15 \%$ is smaller than $50 \mu \mathrm{m}$, therefore with size adequate for pigments industry.

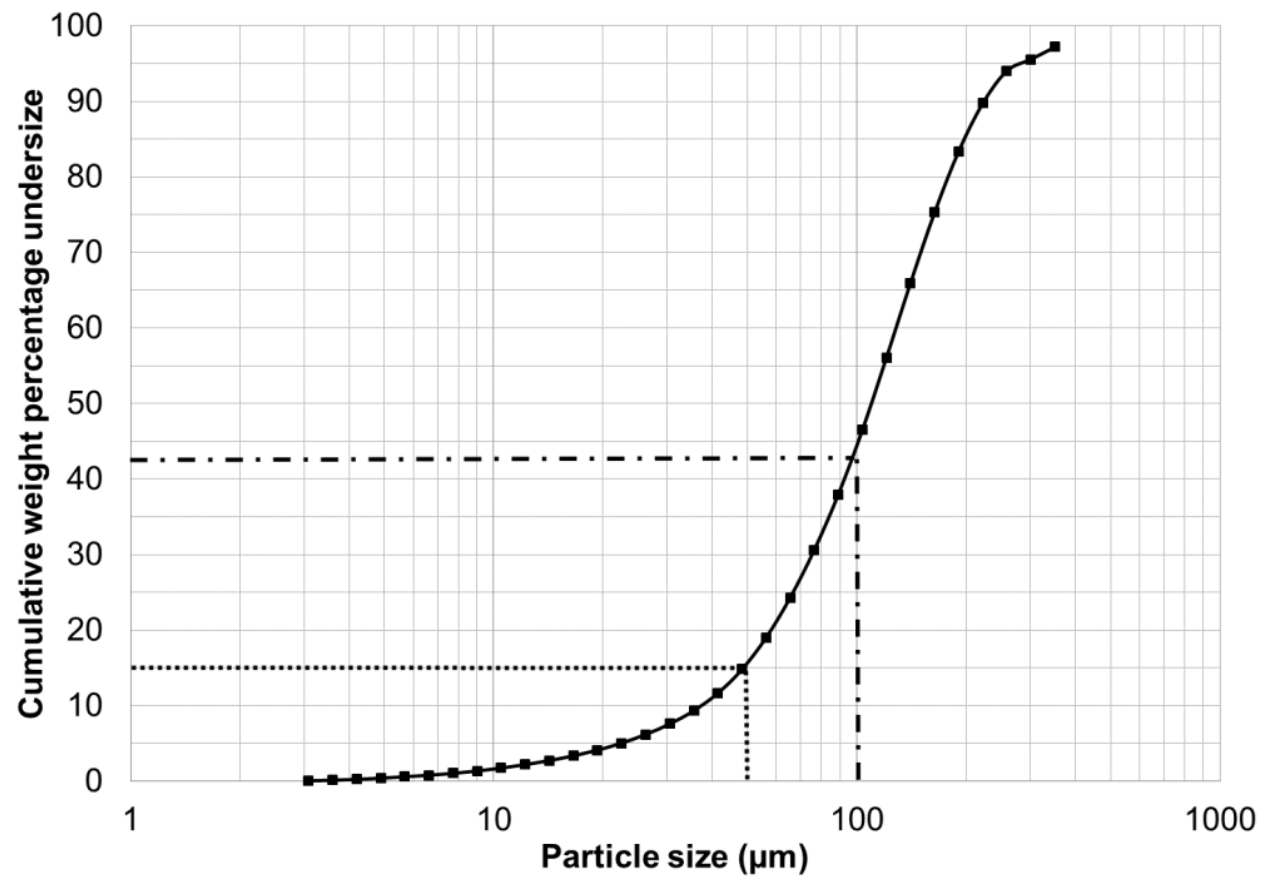

Fig. 1: Magnetite particle size analysis using a laser particle analyser Mastersizer from Malvern.

Table 1 shows the magnetite samples chemical analysis per granulometry. Samples showed a high content of iron oxide, around $78 \%$ for the coarse size $(-500+300 \mu \mathrm{m})$ and higher than $84 \%$ for the other sizes. By contrast, small amounts of silica, titanium, magnesium and phosphate (less than 10\%) and traces of other elements were observed. The $\mathrm{P}_{2} \mathrm{O}_{5}$ indicated that this sample cannot be used in siderurgy to produce pig iron since phosphorus is a contaminant and its content must be lower than $0.05 \%$ (around 50 times less than values observed in the samples).

Table 1: Results of chemical analysis for magnetite samples separated by particle size trough X-ray fluorescence.

\begin{tabular}{|c|c|c|c|c|c|c|c|c|c|c|c|c|c|}
\hline $\begin{array}{c}\text { Particle } \\
\text { size } \\
(\mu \mathrm{m})\end{array}$ & $\mathrm{Fe}_{2} \mathrm{O}_{3}$ & $\mathrm{TiO}_{2}$ & $\mathrm{CaO}$ & $\mathrm{SiO}_{2}$ & $\mathrm{P}_{2} \mathrm{O}_{5}$ & $\mathrm{MgO}$ & $\mathrm{MnO}$ & $\mathrm{Cr}_{2} \mathrm{O}_{3}$ & $\mathrm{Nb}_{2} \mathrm{O}_{5}$ & $\mathrm{ZrO}_{2}$ & $\mathrm{ZnO}$ & $\mathrm{SrO}$ & Others \\
\hline$-500+300$ & 78.943 & 5.480 & 3.512 & 2.691 & 2.643 & 1.986 & 0.601 & 0.118 & 0.195 & 0.132 & 0.114 & 0.090 & 3.495 \\
\hline$-300+212$ & 84.036 & 5.334 & 2.621 & 2.419 & 2.212 & 1.913 & 0.737 & 0.230 & 0.217 & 0.131 & 0.077 & 0.070 & 0.003 \\
\hline$-212+150$ & 85.312 & 5.114 & 2.460 & 1.706 & 2.072 & 1.798 & 0.720 & 0.204 & 0.168 & 0.116 & 0.078 & 0.069 & 0.183 \\
\hline$-150+106$ & 85.367 & 5.443 & 2.180 & 1.315 & 1.900 & 2.019 & 0.765 & 0.480 & 0.187 & 0.135 & 0.096 & 0.066 & 0.047 \\
\hline$-106+75$ & 82.186 & 6.035 & 2.803 & 2.776 & 2.176 & 2.261 & 0.829 & 0.312 & 0.243 & 0.170 & 0.051 & 0.096 & 0.062 \\
\hline$-75+53$ & 85.624 & 5.119 & 2.272 & 1.596 & 1.841 & 1.762 & 0.598 & 0.427 & 0.267 & 0.126 & 0.072 & 0.084 & 0.212 \\
\hline
\end{tabular}


Table 2 shows the sand quartz samples chemical analysis per granulometry. Samples showed a high content of silica, higher than $90 \%$ for all particle sizes. By contrast, small amounts of iron oxide (less or equal to 3\%) and traces of other elements were observed.

Table 2: Results of chemical analysis for quartz sand samples separated by particle size trough X-ray fluorescence.

\begin{tabular}{|c|c|c|c|c|c|c|c|c|c|c|c|c|c|}
\hline $\begin{array}{c}\text { Particle } \\
\text { size } \\
(\mu \mathrm{m})\end{array}$ & $\mathrm{Fe}_{2} \mathrm{O}_{3}$ & $\mathrm{TiO}_{2}$ & $\mathrm{CaO}$ & $\mathrm{SiO}_{2}$ & $\mathrm{P}_{2} \mathrm{O}_{5}$ & $\mathrm{MgO}$ & $\mathrm{MnO}$ & $\mathrm{Cr}_{2} \mathrm{O}_{3}$ & $\mathrm{ZrO}_{2}$ & $\mathrm{ZnO}$ & $\mathrm{Al}_{2} \mathrm{O}_{3}$ & $\mathrm{BaO}$ & $\mathrm{Others}$ \\
\hline$-500+300$ & 1.810 & 0.244 & 0.257 & 94.370 & 0.196 & & & 0.163 & & & 2.485 & 0.100 & 0.375 \\
\hline$-300+212$ & 2.148 & 0.283 & 0.075 & 93.851 & 0.095 & 0.199 & & 0.143 & & & 3.147 & & 0.059 \\
\hline$-212+150$ & 2.246 & 1.088 & 0.310 & 93.345 & 0.203 & & & & 0.027 & & 2.338 & & 0.443 \\
\hline$-150+106$ & 1.652 & 0.849 & & 93.934 & & & & & & & 2.861 & 0.160 & 0.544 \\
\hline$-106+75$ & 2.511 & 1.331 & 0.417 & 90.360 & 0.321 & 0.233 & 0.123 & 0.149 & 0.088 & 0.028 & 3.843 & & 0.596 \\
\hline$-75+53$ & 3.026 & 1.987 & 0.229 & 90.230 & 0.113 & 0.237 & & 0.180 & 0.294 & & 3.614 & & 0.090 \\
\hline
\end{tabular}

Figure 2 shows the SEM results for samples of magnetite and quartz sands. It is possible to notice that the morphology of the particles (both magnetite and quartz sand) are quite similar, even in different sizes.

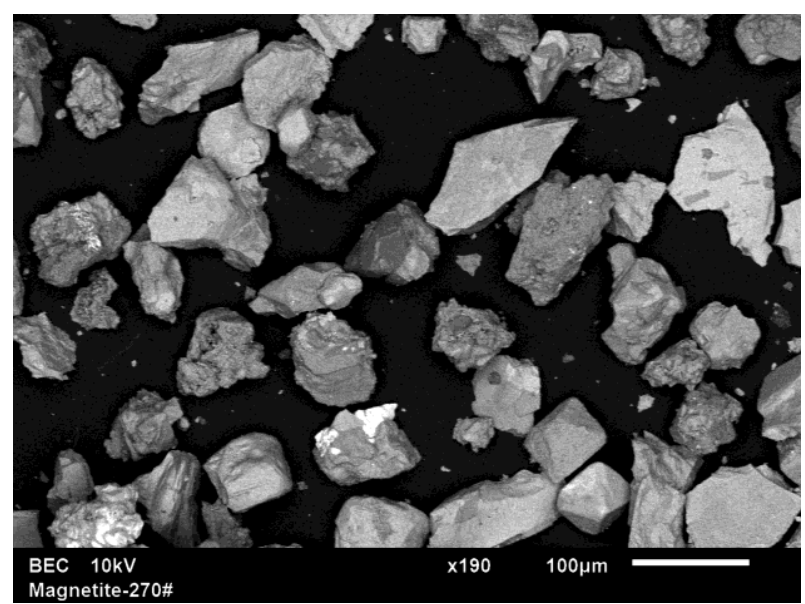

(a)

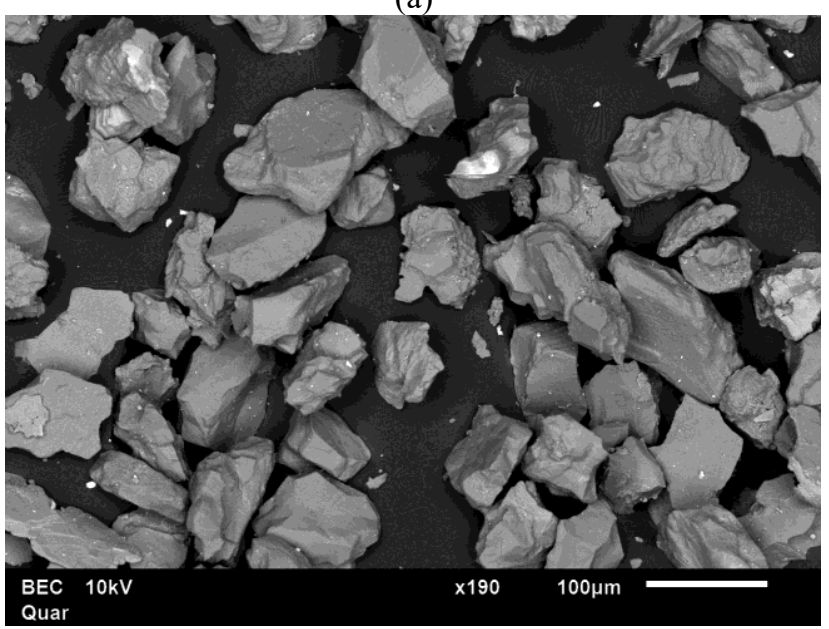

(c)

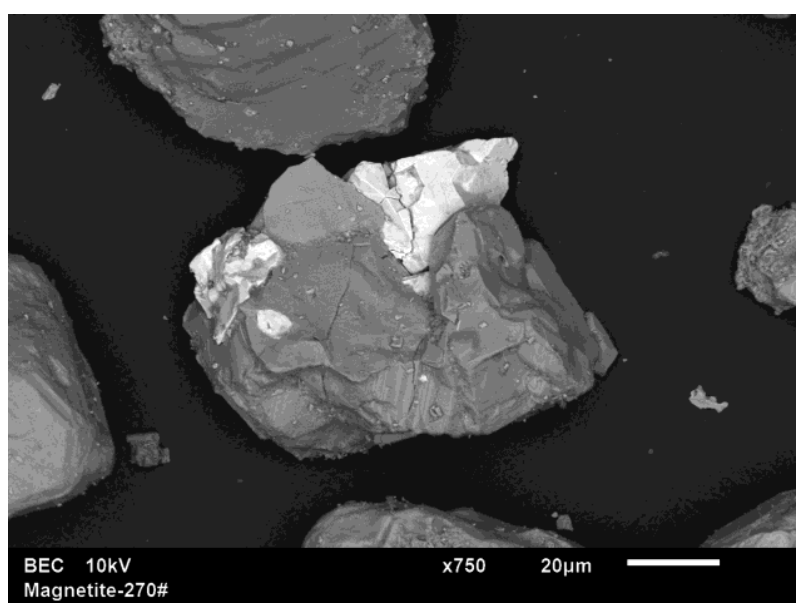

(b)

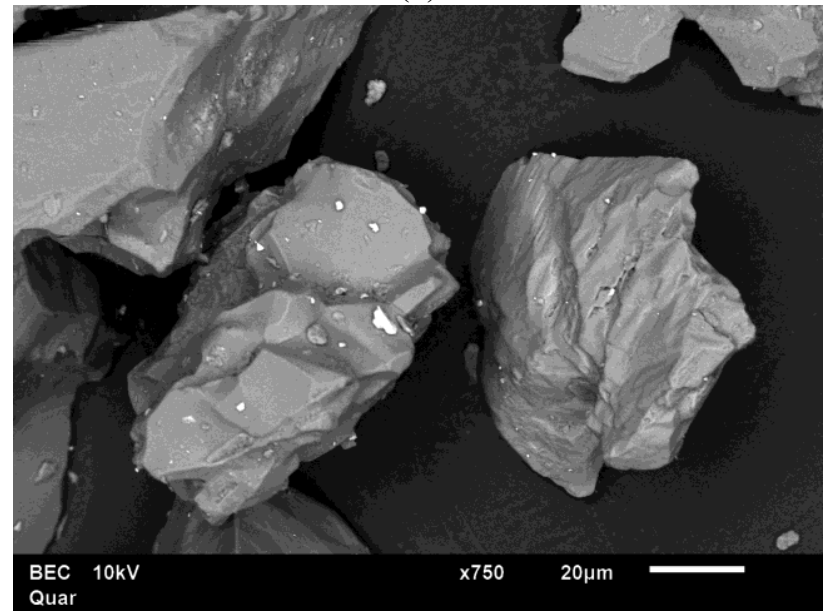

(d)

Fig. 2: SEM results for (a) and (b) magnetite sample at $-75+53 \mu \mathrm{m}$ and (c) and (d) quartz sand sample at $-106+75 \mu \mathrm{m}$. 
Figures 3 shows the results for EDS analyses in three different points for magnetite samples $-75+53 \mu \mathrm{m}$ and figure 4 for quartz sand $-106+75 \mu \mathrm{m}$. In both cases, the punctual chemical analyses provided by the EDS were similar to the results obtained through X-ray fluorescence. In figure 3 it is possible to see that niobium bearer minerals are associated my magnetite even in small particle sizes (see point 2 in figure 3a). The liberation degree of these minerals is normally lower at this particle size and further comminution is required before the niobium's froth flotation stages. The average particle size used in this froth flotation is between $-53+37 \mu \mathrm{m}$. Similar results regarding liberation degree were obtained for quartz sand (see point 5 in figure 4a). The other minerals present in the quartz sand were attached to the quartz particles and not liberated. Since mineral particles were attached in both samples (magnetite and quartz sands) the density of both mineral are expected to be different of pure minerals, but close to it.

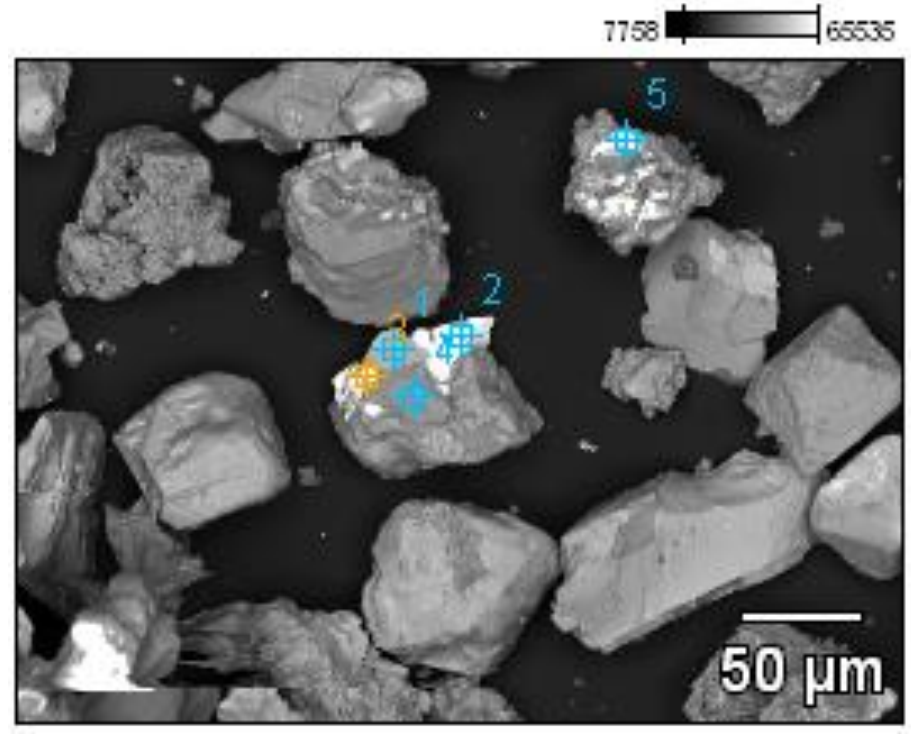

Sample: Magnetite $-75+53 \mu \mathrm{m}$

Accelerating Voltage: $10.0 \mathrm{kV}$

Magnification: 330

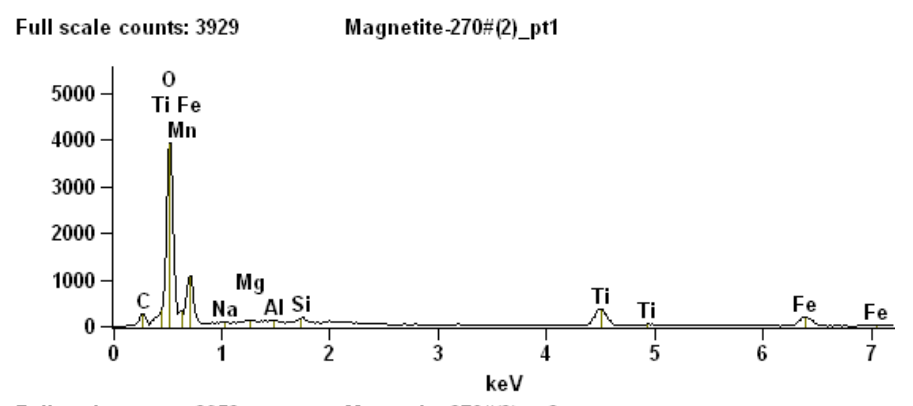

Full scale counts: $2953 \quad$ Magnetite-270\#(2)_pt2

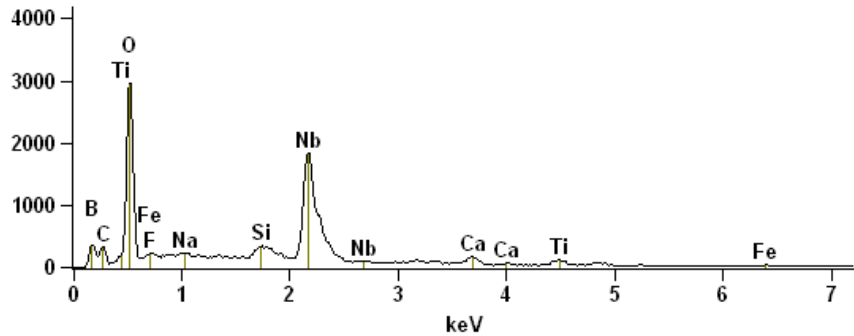

Full scale counts: $4752 \quad$ Magnetite-270\#(2)_pt4

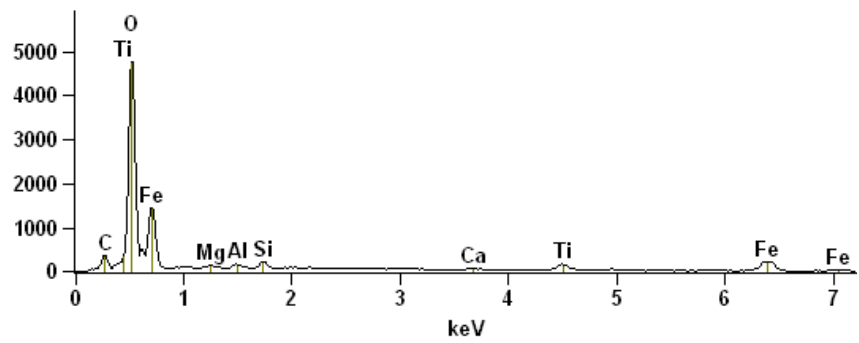

(b)

(a)

Fig. 3: EDS results for magnetite sample $-75+53 \mu \mathrm{m}$. (a) SEM image and (b) EDS results for three different points.

Figure 5 shows the average magnetite recovery and grade in sunk due according the particle size for each tested pulsation frequency. The black dotted lines represent magnetite grade and the red solid lines represent magnetite recovery. The error bar has been suppressed to avoid information overload in the figures. For all tested frequencies, the best values for grades occur in the finer fractions. On the other hand, the best results for magnetite recovery happened for coarser particles (above $150 \mu \mathrm{m}$ ). It can be seen that for pulsation frequencies of 274 and 359 RPM and particle size under $100 \mu \mathrm{m}$ the magnetite recoveries was around $40 \%$ and grades above $95 \%$.

Figures 6 a shows grades and $6 \mathrm{~b}$ recoveries obtained versus particle size and jig pulsation frequency, where the warmer colours represent higher levels and cooler colours represent lower levels. It is noted that particle size has more influence on jigging, since at any pulsation frequency was possible to obtain concentrates above $90 \%$ magnetite content in the particle sizes under $106 \mu \mathrm{m}$. 


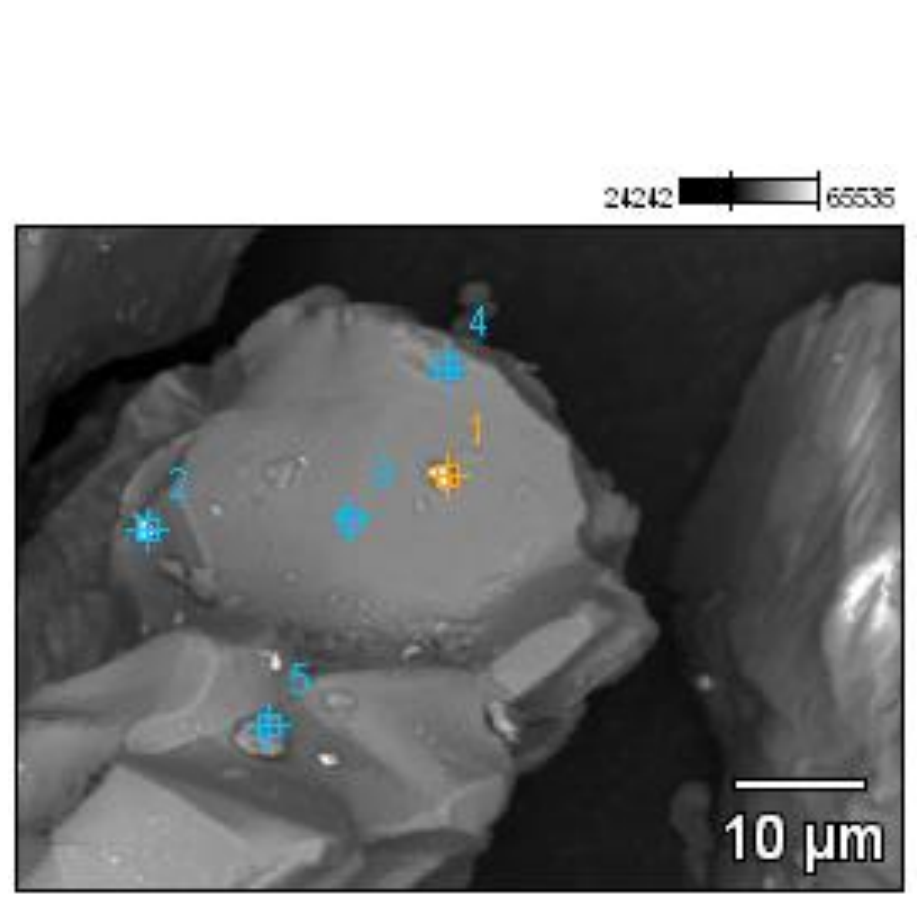

Full scale counts: 6206

Quart-200\#(2)_pt1

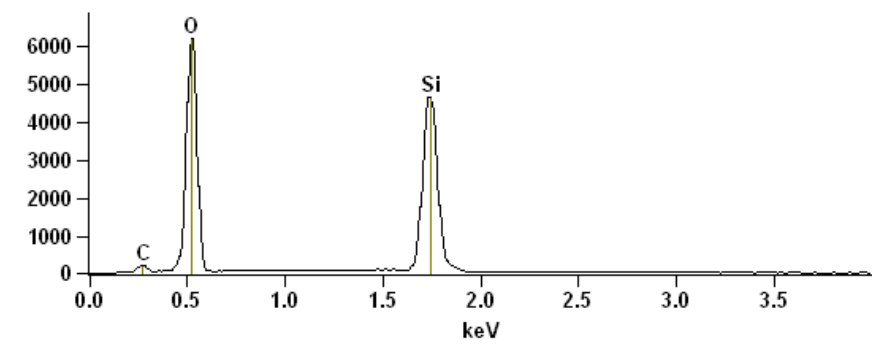

Full scale counts: $276 \quad$ Quart-200\#(2)_pt2

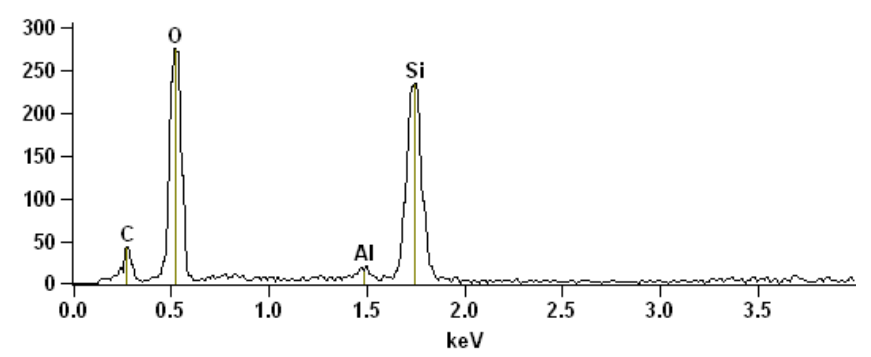

Full scale counts: $6247 \quad$ Quart-200\#(2)_pt5

Sample: Quartz sand $-106+75 \mu \mathrm{m}$

Accelerating Voltage: $10.0 \mathrm{kV}$

Magnification: 1800

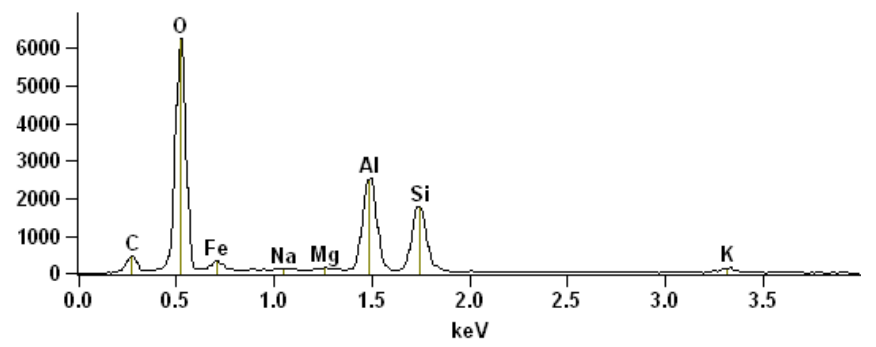

(b)

(a)

Fig. 4: EDS results for quartz sand sample $-106+75 \mu \mathrm{m}$. (a) SEM image and (b) EDS results for three different points.

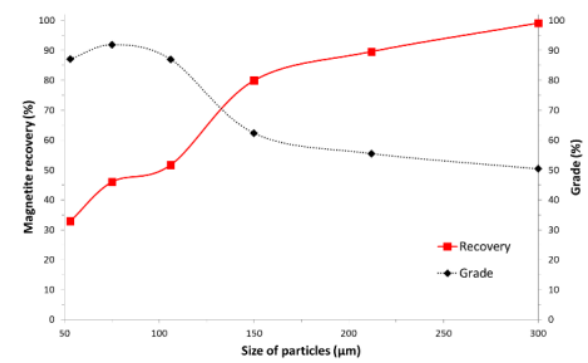

(a)

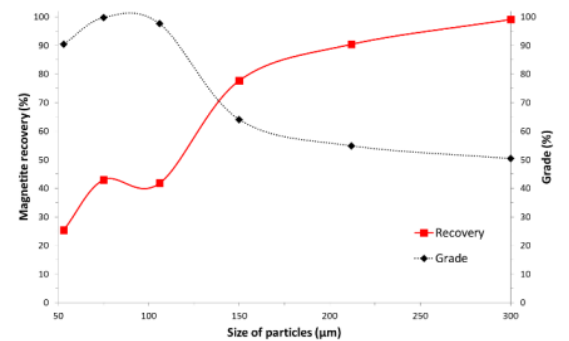

(c)

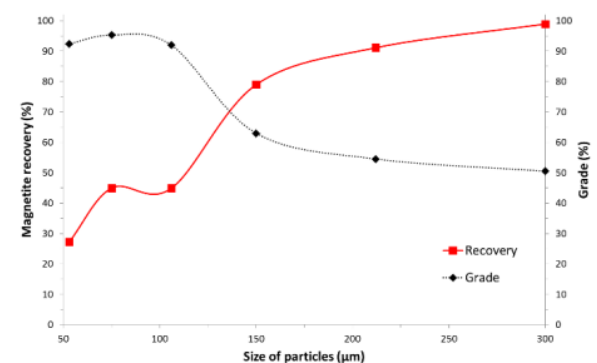

(b)

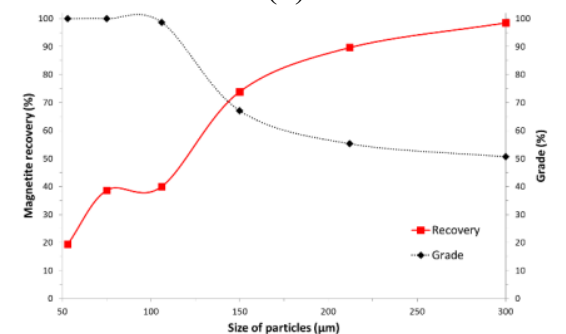

(d)

Fig. 5: Magnetite recovery results and tests grades for each frequency (a) 102 (b) 188 (c) 274 and (d) 359 RPM. 


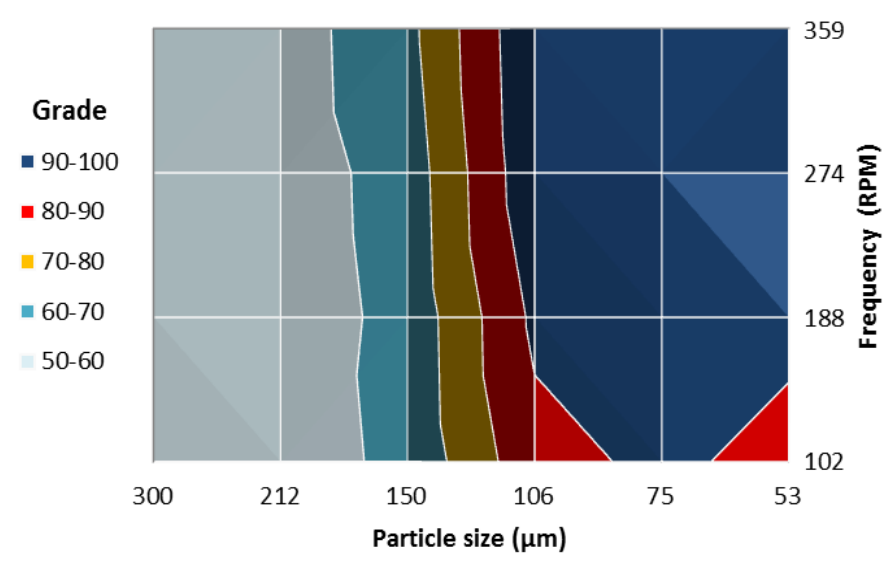

(a)

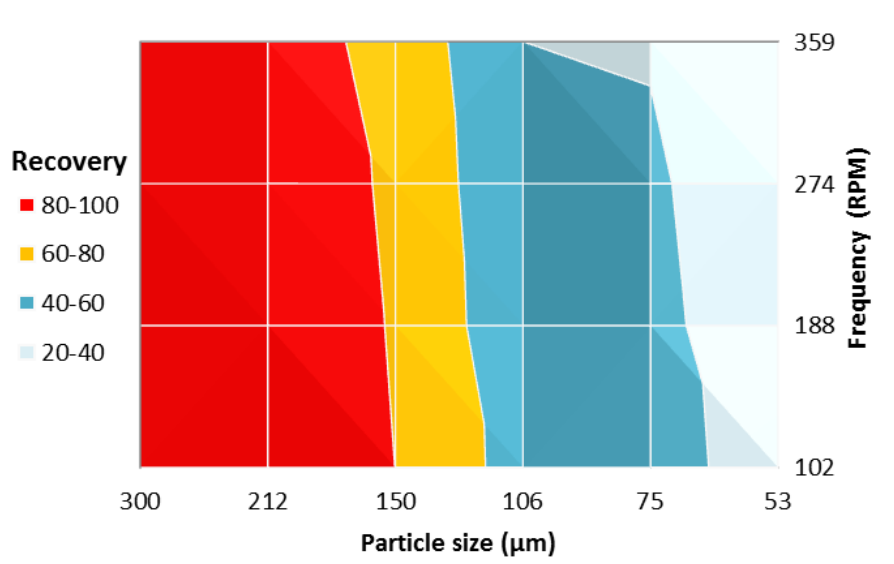

b)

Fig. 6: Jigging results in relation to the particle size and pulsation frequency for magnetite (a) grade and (b) recovery.

\section{Conclusion}

The test results has shown that there is a magnetite enrichment and a decrease of quartz sand content in the sunk material after the jigging. Thus, it follows that the jigging procedure was effective in separating these two minerals. The samples showed a clear trend of purification for the finer fractions, independent of the adopted pulsation frequency, which means that particle size is a more important factor than the pulsation frequency for this type of jig.

For the production of pigments, it is necessary that the particle size is at most $100 \mu \mathrm{m}$, with a purity of $90 \%$. For these parameters, the magnetite recovery was close to $40 \%$. From the granulometric analysis is possible to notice that $45 \%$ of the material thrown nowadays in the tailings dam is below $100 \mu \mathrm{m}$, and thus, if a jig was introduced at the end of the process to produce magnetite, Anglo American Phosphate could produce approximately 360,000 tons per year of magnetite under pigments specification. It is also possible to insert a milling process before the jig, making the tailings recovery even greater.

\section{Acknowledgements}

The authors thank financial support from the Brazilian agencies CNPq, CAPES, FAPEG and FUNAPE. In addition, we like to thank Anglo American for the samples donation and chemical analyses, Federal University of Goiás and Goiano Federal Institute.

\section{References}

[1] R. G. Casqueira and S. F. Santos, Pigmentos inorgânicos: propriedades, métodos de síntese e aplicações. Rio de Janeiro: CETEM/MCT, 2008, pp. 46.

[2] F. M. Barros, P. M. T. Cavalcante, M. C. Andrade, A. B. Luz, and J. A. Sampaio, "Beneficiamento do rejeito de moscovita da região do seridó-borborema (NE) para aproveitamento industrial," in Proc. of XXI National Meeting of Mineral Processing and Extractive Metallurgy, 2005, pp. 199-205.

[3] T. C. C. Costa, "Síntese de nanopartículas de magnetita via decomposição térmica em meio não-aquoso," UFRGN, pp. 58, 2013.

[4] E. G. Kelly and D. J. Spottiswood, Introduction to Mineral Processing. John Wiley \& Sons, 1982.

[5] M. Tsunekawa, B. Naoi, S. Ogawa, K. Hori, N. Hiroyoshi, M. Ito, and T. Hirajima, "Jig separation of plastics from scrapped copy machines," International Journal of Mineral Processing, vol. 76, pp. 67-74, 2005.

[6] G. Agricola, "De Re Metallica," Translated by H. C. Hoover and L. H. Hoover, Dover reprint of 1912 edition, New York. 1950.

[7] A. K. Mukherjee and B. K. Mishra, "An integral assessment of the role of critical process parameters on jigging," International Journal of Mineral Processing, vol. 81, pp. 187-200, 2006.

[8] K. Hori, M. Tsunekawa, N. Hiroyoshi, and M. Ito, "Optimum water pulsation of jig separation for crushed plastic particles,” International Journal of Mineral Processing, vol. 92, pp. 103-108, 2009.

[9] A. K. Mukherjee, V. K. Dwivedi, and B. K. Mishra, "Analysis of a laboratory jigging system for improved performance," Mineral Engineering, vol. 18, pp. 1037-1044, 2005. 
[10] B. K. Mishra and S. P. Mehrotra, "Modelling of particle stratification in jigs by the discrete element method," Mineral Engineering, vol. 11, no. 6, pp. 511-522, 1998.

[11] H. Kellerwessel. "Concentration by jigging - current investigations, concepts and models," Aufbereit.-Tech., vol. 39, pp. 9-15, 1998.

[12] A. J. Clarke, X. Jia, R. A. Williams, and D. J. Parker, "Verification of distinct element modelling of particle segregation in laboratory jigs using positron emission tomography," in Proc. of Frontiers in Industrial Process Tomography II, Engineering Foundation/Technical, New York: University of Delft. 1997, pp. 91-96.

[13] B. K. Mishra, and S. P. Mehrotra, "A jig model based on the discrete element method and its experimental validation," International Journal of Mineral Processing, vol. 63, pp. 177-189, 2001.

[14] R. S. Tomaz, A. C. Silva, E. M. S. Silva, D. N. Sousa, and C. M. Silva Filho, "Barite and magnetite production from phosphate rock ore by jigging," in Proc. of 2nd International Symposium on Sustainable Mineral Processing, Antalya, Turkey, 2015, pp. 97-104. 